\title{
QUALIDADE FÍSICA DO SOLO EM POMAR DE LARANJEIRA NO NOROESTE DO PARANÁ COM MANEJO DA COBERTURA PERMANENTE NA ENTRELINHA ${ }^{(1)}$
}

\author{
Jonez Fidalski ${ }^{(2)}$, Cássio Antonio Tormena ${ }^{(3)} \&$ Álvaro Pires da Silva ${ }^{(4)}$
}

\begin{abstract}
RESUMO
O tráfego de máquinas e a compactação do solo ocorrem próximo à copa das plantas de citros, aumentando as restrições físicas do solo ao crescimento das raízes. Estratégias de manejo incluem o uso de coberturas permanentes do solo nas entrelinhas de pomares de laranjeira, mas são desconhecidos os seus efeitos na qualidade física do solo. O objetivo deste estudo foi quantificar o impacto de sistemas de manejo com cobertura permanente do solo em alguns indicadores de qualidade física do solo em um pomar de laranjeira. O estudo foi realizado em um experimento de longa duração de laranjeira 'Pêra' sobre limoeiro 'Cravo' com sistemas de cobertura permanente do solo nas entrelinhas, no município de Alto Paraná, noroeste do Paraná, em um Argissolo Vermelho distrófico latossólico, com horizonte superficial de textura arenosa. Os tratamentos de cobertura permanente nas entrelinhas com a gramínea mato-grosso ou batatais (Paspalum notatum) manejada com roçada e a leguminosa amendoim forrageiro (Arachis pintoi) foram comparados ao manejo tradicional, em que a vegetação espontânea foi dessecada com herbicida pós-emergente. $O$ delineamento experimental utilizado foi de bloco ao acaso com três repetições. Em maio de 2003, a amostragem de solo foi realizada sob rodado e entrerrodado das máquinas nas entrelinhas do pomar. As amostras indeformadas de solo obtidas no centro da camada de $0-15 \mathrm{~cm}$ de profundidade foram utilizadas para determinação dos seguintes indicadores: conteúdo de água na capacidade de campo, porosidade total do solo e densidade do solo, a partir dos quais foram estimados os indicadores capacidade de aeração do solo e capacidade de armazenamento de água do solo. Amostras de solo deformadas foram coletadas nas camadas de 0-5 e 10-15 cm de profundidade, para determinação dos teores de C orgânico do solo e cálculo da taxa de estratificação de C orgânico do solo. Os indicadores de qualidade do solo, capacidade de armazenamento de água do solo, capacidade de aeração do solo e taxa de estratificação de C orgânico do solo foram
\end{abstract}

(1) Parte da Tese de Doutorado do primeiro autor. Programa de Pós-Graduação em Agronomia - Solos e Nutrição de Plantas, Universidade Estadual de Maringá (UEM). Recebido para publicação em janeiro de 2006 e aprovado em março de 2007.

(2) Pesquisador do Instituto Agronômico do Paraná - IAPAR. Área de Solos. Caixa Postal 564, CEP 87701-970 Paranavaí (PR). Email: fidalski@iapar.br

(3) Professor Associado, Departamento de Agronomia, Universidade Estadual de Maringá - UEM. Av. Colombo 5790, CEP 87020900 Maringá (PR). Bolsista do CNPq. E-mail: catormena@uem.br

(4) Professor Titular, Departamento de Solos e Nutrição de Plantas, Escola Superior de Agricultura "Luiz de Queiroz" - ESALQ/ USP. Caixa Postal 09, Av. Pádua Dias 11, CEP 13418-900 Piracicaba (SP). Bolsista do CNPq. E-mail: apisilva@esalq.usp.br 
eficientes na avaliação de sistemas de manejo de solo em citros. A manutenção da vegetação das entrelinhas vegetadas com a gramínea mato-grosso ou batatais melhora a qualidade física do solo, independentemente das posições rodado e entrerrodado. A qualidade física do solo é afetada negativamente na posição rodado sob o manejo com amendoim forrageiro e nas posições rodado e entrerodado no manejo tradicional da vegetação espontânea com herbicida pós-emergente.

Termos de indexação: porosidade do solo, aeração do solo, retenção de água, propriedades físicas, matéria orgânica do solo.

\section{SUMMARY: SOIL PHYSICAL QUALITY IN AN ORANGE ORCHARD IN NORTHWESTERN PARANA AS AFFECTED BY GROUNDCOVER MANAGEMENT}

The traffic of agricultural machinery and soil compaction occur near the canopy of citrus trees, which increases soil physical restrictions to root growth. Soil management strategies include the use of permanent groundcover in the interrows of orange tree plantations, although the effects of these practices on the soil physical quality are largely unknown. The objective of this study was to assess the impact of groundcover management systems on some indicators of soil physical quality for orange tree orchards. The study was performed in a long-term experiment with 'Pêra' orange grafted onto 'Rangpur' lime combined with groundcover systems, established in 1993, in the Alto Paraná county, northwestern Paraná state, Brazil, in a Typic Paleudult with a sandy surface horizon. Bahiagrass (Paspalum notatum) or perennial peanut (Arachis pintoi) groundcover treatments were compared with the usual management in which weeds are controlled by post-emergence herbicide. The experimental design consisted of randomized blocks with three replications. In May 2003, soil samples were collected from under and between the wheel tracks. The following indicators were assessed in undisturbed soil samples from the mid $0-15 \mathrm{~cm}$ layer: water content at field capacity, total porosity and bulk density. The data were used to estimate soil aeration and water storage capacity indicators. Disturbed soil samples were collected in the $0-5 \mathrm{~cm}$ and $10-15 \mathrm{~cm}$ depths to measure the organic carbon content and calculate the soil organic carbon stratification ratio. The soil aeration capacity, water storage capacity and organic carbon stratification ratio were efficient indicators to evaluate groundcover management systems in citrus. Bahiagrass maintained better soil physical conditions both under and between wheel tracks. The soil physical quality was negatively affected under the wheel tracks on perennial peanut groundcover and under the wheel tracks and between tracks on the usual control of spontaneous vegetation with postemergence herbicide.

Index terms: soil porosity, soil aeration, water retention, soil physical properties, soil organic matter.

\section{INTRODUÇÃO}

A citricultura paranaense foi implantada com critérios técnicos que levaram em conta a capacidade de uso dos solos, destacando-se a manutenção da cobertura vegetal nas entrelinhas dos pomares de laranjeira (Rufino et al., 1992), especificamente para os solos originários da formação Caiuá, caracterizados pelos baixos teores de argila e C orgânico na camada superficial (Embrapa, 1984; Fidalski, 1997a). Esses solos apresentam elevada suscetibilidade à erosão, baixa disponibilidade de água e são altamente frágeis para sustentar a produção agrícola em sistemas intensivos de exploração (Embrapa, 1984; Fidalski, 1997b). Sistemas de manejo que melhorem e mantenham a qualidade do solo para fins agrícolas e ambientais são necessários nesse contexto.

$\mathrm{Na}$ atualidade, as avaliações de sistemas de manejo nas entrelinhas dos pomares de citros requerem a inclusão da posição de amostragem referente à zona de tráfego de máquinas caracterizada como rodado, devido à concentração do tráfego de máquinas neste local (Lima et al., 2004; Fidalski et al., 2007). O tráfego de máquinas ocorre muito próximo da zona de adubação, distante cerca de $0,5 \mathrm{~m}$ do limite externo da projeção da copa das laranjeiras. Nessas condições, a degradação física do solo resultante da compactação pode comprometer a eficiência da adubação e a produtividade dos pomares. No Brasil, é reconhecido que o manejo mecanizado na cultura dos citros resulta 
na heterogeneidade das propriedades físicas do solo, como demonstrado nos estudos de Sanches et al. (1999), Lima et al. (2004) e Fidalski et al. (2007).

A avaliação dos impactos de sistemas de manejo em pomares de laranjeira baseia-se na quantificação de propriedades do solo nas entrelinhas dos pomares, correspondendo, provavelmente, à posição de amostragem de solo no entrerrodado (Pacheco et al. 1975; Koller et al., 1978; Cintra et al., 1983). As interpretações obtidas em estudos dessa natureza não consideraram a heterogeneidade física do solo resultante do manejo da cultura, tampouco quantificam se determinado sistema de manejo degradou, manteve ou melhorou a qualidade do solo (Karlen et al., 2001). Essa qualidade é definida como a capacidade de um solo exercer suas funcões dentro dos limites naturais ou de um ecossistema manejado para sustentar a produtividade de planta e animal, manter ou melhorar a qualidade da água e do ar, bem como servir de suporte à habitação e à saúde humana (Karlen et al., 1997). Estratégias simples, eficazes e de baixo custo para avaliação da qualidade do solo são necessárias, a exemplo das apresentadas por Franzluebbers (2002) e Reynolds et al. (2002).

Diferentes propriedades físicas têm sido usadas na quantificação da qualidade física do solo (Topp \& Zebchuk, 1979); dentre estas, a densidade e a porosidade são as mais amplamente utilizadas. Do ponto de vista biológico, um solo com boa qualidade física requer balanço entre aeração e retenção de água, além de resistência do solo à penetração não impeditiva ao crescimento e às funções fisiológicas das raízes (Letey, 1985). Os resultados de Skopp et al. (1990) indicam que a máxima atividade biológica, medida pela liberação de $\mathrm{N}$ disponível às plantas via mineralização da matéria orgânica, ocorreu quando a saturação relativa do solo foi de $66 \%$ ou, complementarmente, com $34 \%$ do seu espaço poroso ocupado com ar. Essas proporções são medidas em potencial mátrico correspondente à capacidade de campo, considerandose o teor de água retido e a capacidade de aeração total do solo, em relação à porosidade total.

$\mathrm{Na}$ avaliação de diferentes indicadores, Reynolds et al. (2002) não verificaram diferenças consistentes entre sistemas de manejo de solo sob plantio direto e convencional. Esses autores, após terem explorado os indicadores capacidade de aeração total do solo e capacidade de armazenamento de água do solo, reiteraram os valores referenciais de Skopp et al. (1990), de 0,66 e 0,34 , respectivamente, em solos com teores de argila de 160 a $370 \mathrm{~g} \mathrm{~kg}^{-1}$, apesar de eles não terem sido constatados em solo com teor de argila de $50 \mathrm{~g} \mathrm{~kg}^{-1}$.

Outros indicadores de qualidade física do solo foram propostos por Reynolds et al. (2002), como a porosidade no domínio dos macroporos e a porosidade da matriz do solo, equivalentes aos diâmetros de poros superiores e inferiores a $300 \mu \mathrm{m}$, respectivamente. Os autores justificam o desdobramento dessas duas classes de poros, porque elas distinguem as funções de armazenamento e transmissão de água e ar. Paralelamente, Reynolds et al. (2002) sugeriram os indicadores de qualidade do solo denominados capacidade de aeração da matriz do solo e capacidade de aeração total do solo, utilizando como referência o potencial mátrico do solo saturado e os poros equivalentes a diâmetros inferiores a $300 \mu \mathrm{m}$ ou drenados no potencial mátrico de $-1 \mathrm{kPa}$, respectivamente, em relação ao potencial mátrico correspondente à capacidade de campo.

O conteúdo de matéria orgânica não é propriamente um indicador de qualidade física do solo, mas influencia direta e indiretamente várias propriedades que estabelecem a sua qualidade física (Christensen \& Johnston, 1997). Em adição ao valor absoluto do teor de C orgânico do solo, Franzluebbers (2002) utilizou a taxa de estratificação de C orgânico do solo como indicador de sua qualidade, que consiste no quociente dos valores de C orgânico da camada de 0-5 cm com aqueles da camada de $15-20 \mathrm{~cm}$ de profundidade. Esse procedimento permite a normalização dos dados e a comparação entre diferentes solos e sistemas de manejo, tendo como referência o valor igual ou superior a duas unidades, visto que não é comum a ocorrência desses valores em solos degradados. As vantagens do uso da taxa de estratificação de C orgânico do solo como indicador da qualidade deste é a praticidade e o baixo custo de sua quantificação.

A taxa de estratificação de C orgânico do solo, entre as camadas de 0-5 e 10-15 cm, foi usada por Mrabet (2002) na África, que confirmou a melhor qualidade do solo sob o sistema plantio direto em relação ao preparo convencional, com taxas de estratificação de C orgânico do solo superior e inferior a duas unidades, respectivamente. Contudo, essa estratégia ainda é muito pouco utilizada na avaliação de sistemas de manejo em solos brasileiros, à exceção de Tormena et al. (2004), os quais constataram maior taxa de estratificação de C orgânico do solo em plantio direto, comparado ao plantio direto com escarificação. Paralelamente, Kay \& VandenBygaart (2002) e Emerson \& McGarry (2003) demonstraram a influência do teor de C orgânico do solo na sua porosidade, sugerindo relações entre esta variável e o teor de água retida no potencial mátrico de -10 kPa. Originalmente, Hollis et al. (1977) relacionaram o conteúdo de água retido no potencial mátrico de $-5 \mathrm{kPa}$ e os teores de $\mathrm{C}$ de 144 horizontes superficiais de solos.

Os indicadores de qualidade do solo preconizados por Reynolds et al. (2002) e Franzluebbers (2002) foram quantificados em solos de clima temperado e, ainda, não foram utilizados na avaliação da qualidade física em solos tropicais e subtropicais brasileiros. O objetivo deste estudo foi quantificar o impacto de sistemas de manejo com cobertura permanente do solo em alguns indicadores de sua qualidade física em pomar de laranjeira, com manejo da cobertura permanente na entrelinha, no noroeste do Paraná. 


\section{MATERIAL E MÉTODOS}

$\mathrm{O}$ estudo foi realizado em um experimento de sistemas de manejo de solo nas entrelinhas de um pomar de laranjeira 'Pêra' Citrus sinensis (L.) Osb. enxertado sobre o limoeiro 'Cravo' Citrus limonia Osb. O experimento foi implantado em 1993, pelo Instituto Agronômico do Paraná (Iapar), na Fazenda São Judas Tadeu, município de Alto Paraná, noroeste do Paraná $\left(23^{\circ} 5^{\prime} \mathrm{S}, 52^{\circ} 26^{\prime} \mathrm{W}\right.$ e altitude de $\left.480 \mathrm{~m}\right)$. O clima na região é subtropical (Cfa), caracterizado pela época de maior precipitação entre outubro e março e sem estação seca definida (Iapar, 2000). No quadro 1 são apresentadas as características granulométricas, porcentagem de areia fina e grossa e saturação por bases do Argissolo Vermelho distrófico latossólico textura arenosa/média A moderado, relevo suaveondulado, com $4 \mathrm{~cm} \mathrm{~m}^{-1}$ de declive (Embrapa, 2006).

A implantação deste experimento consistiu do preparo do solo com aração e gradagem a 0-20 cm de profundidade, em uma área de pastagem de braquiária
Brachiaria humidicola (Rendle) Schweickt. Em 1993, paralelamente ao plantio das mudas de laranjeiras no espaçamento de $7 \times 4 \mathrm{~m}$, em duas entrelinhas paralelas à linha central de cinco plantas, constituindo parcelas experimentais com 15 plantas de laranjeiras (Figura 1), foram implantados os tratamentos, consistindo do plantio de mudas da gramínea matogrosso ou batatais Paspalum notatum (Flügge); semeadura da leguminosa amendoim forrageiro Arachis pintoi (Krap. \& W.C. Greg.); e plantio de mudas de abacaxi em fileira dupla (Fidalski et al., 1999), distantes $1,5 \mathrm{~m}$ do tronco das laranjeiras. A partir de 1996, após a fase de formação do pomar, para possibilitar o tráfego de máquinas e equipamentos agrícolas, a cultura do abacaxi foi substituída pela manutenção da cobertura do solo nas entrelinhas com vegetação espontânea dessecada com herbicida pós-emergente (Glyphosate).

No período de 1996 a 2002, as copas das laranjeiras apresentavam diâmetros de $4 \mathrm{~m}$, com a manutenção das vegetações em entrelinhas de $2 \mathrm{~m}$ de largura e

Quadro 1. Granulometria e saturação por bases (V) nos horizontes do Argissolo Vermelho distrófico latossólico

\begin{tabular}{|c|c|c|c|c|c|c|c|}
\hline \multirow[t]{2}{*}{ Horizonte } & \multirow[t]{2}{*}{ Profundidade } & \multirow[t]{2}{*}{ Argila } & \multirow[t]{2}{*}{ Silte } & \multicolumn{3}{|c|}{ Areia } & \multirow[t]{2}{*}{$\mathrm{V}$} \\
\hline & & & & Total & Fina & Grossa & \\
\hline \multicolumn{3}{|c|}{$\mathrm{cm}$} & & \multicolumn{3}{|c|}{$-\mathrm{g} \mathrm{kg}^{-1}$} & $\%$ \\
\hline $\mathrm{A}$ & $0-6$ & 90 & 30 & 880 & 650 & 230 & 60 \\
\hline $\mathrm{AB}$ & $7-25$ & 70 & 20 & 910 & 640 & 270 & 25 \\
\hline $\mathrm{Bt}$ & $26-55$ & 180 & 20 & 800 & 570 & 230 & 30 \\
\hline $\mathrm{Bw}$ & $56-200$ & 210 & 20 & 770 & 560 & 210 & 17 \\
\hline
\end{tabular}

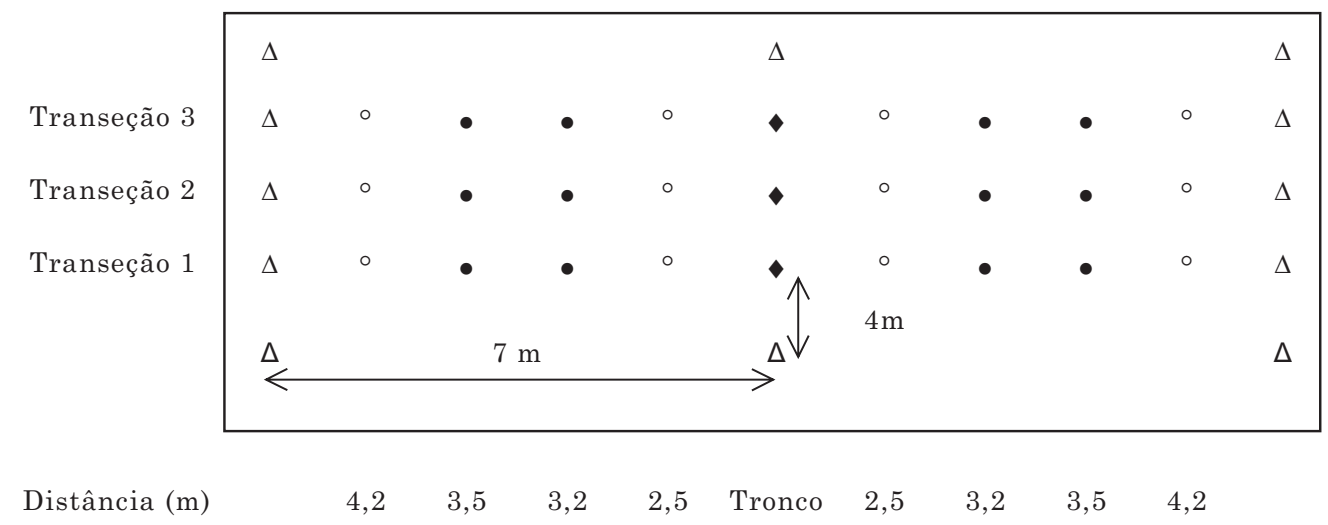

Figura 1. Parcela experimental com três laranjeiras úteis ( $\bullet), 12$ laranjeiras de bordadura $(\Delta), 12$ pontos de amostragem de solo no rodado (o) e 12 pontos de amostragem do entrerrodado ( $(0)$, com a indicação das respectivas distâncias do tronco das laranjeiras úteis, e o espaçamento de 7 x 4 m, entre e dentro das linhas das laranjeiras, respectivamente. 
uma faixa de 0,5 $\mathrm{m}$ adjacente às laranjeiras sem vegetação controlada com herbicida. O tratamento gramínea proporcionou excelente cobertura do solo com predominância de Paspalum notatum, exigindo uma roçada mecânica por ano, realizada preferencialmente no final da estação de chuvas (março), quando essa vegetação atingia altura aproximada de $30 \mathrm{~cm}$. Por sua vez, o tratamento leguminosa com Arachis pintoi caracterizou-se pela sazonalidade da cobertura vegetal, observada pela redução da produção de biomassa nos períodos de estiagem e geada, implicando a infestação de outras espécies, principalmente a guanxuma Sida rhombifolia (L.) e, em menor proporção, o capimamargoso Digitaria insularis (L.) Fedde, cujo controle vinha sendo realizado até 1998 , por meio de capina manual. A partir de 1999, optou-se por não mais intervir na população dessas espécies, sendo observado aumento de guanxuma, que exigiu o controle por meio de roçadas mecânicas em dezembro de 2001 e novembro de 2002 , de modo que não interferisse no crescimento da leguminosa. Inicialmente a vegetação espontânea foi controlada com o propósito de se manter baixa cobertura do solo, tendo sido utilizada em 1998, 1999 e 2000 três, duas e uma aplicação de herbicida pós-emergente (Glyphosate), respectivamente. A redução progressiva do número de aplicações de herbicida se deve à manutenção do solo parcialmente descoberto até 2001 e ao aumento da infestação pelo agriãozinho Synedrellopsis grisebachii (Hieron. \& Kuntze), de hábito de crescimento rasteiro, associado a outras 21 espécies de plantas em março de 2003 (Fidalski, 2004), resultando em baixa produção de resíduos vegetais.

O controle fitossanitário, a adubação mineral e a calagem foram realizados conforme as recomendações técnicas para a cultura de citros (Iapar, 1992; Grupo Paulista de Adubação e Calagem para Citros, 1994). Quanto aos tratos fitossanitários, adubação, calagem, controle da vegetação e colheita de frutos, foram utilizados roçadora mecânica, pulverizador com capacidade de $2.000 \mathrm{~L}$ e trator de pneu, com massas aproximadas de 500, 1.000 e $4.000 \mathrm{~kg}$, respectivamente.

O delineamento experimental utilizado foi de blocos ao acaso, dispostos perpendicularmente ao declive do terreno, com três repetições. Foram avaliados três tratamentos de cobertura permanente nas entrelinhas, com as seguintes vegetações: (a) gramínea grama mato-grosso ou batatais (Paspalum notatum); (b) leguminosa - amendoim forrageiro (Arachis pinto1); e (c) espontânea - manejo tradicional, em que as plantas são dessecadas com herbicida.

Na primeira quinzena de maio de 2003 foi realizada a amostragem do solo nas entrelinhas do pomar, sob o rodado e entrerrodado das máquinas. Os pontos de amostragem foram referenciados em três transeções aos troncos das três laranjeiras úteis de cada parcela experimental: sob o rodado (2,5 e 4,2 m à esquerda e à direita do tronco das laranjeiras) e sob o entrerrodado (3,2 e $3,5 \mathrm{~m}$ à esquerda e à direita do tronco das laranjeiras) (Figura 1). Amostras indeformadas de solo foram coletadas no centro da camada de $0-15 \mathrm{~cm}$ de profundidade, utilizando-se anéis metálicos com dimensões de $5 \mathrm{~cm}$ de diâmetro e altura, totalizando 216 amostras. Após o preparo dessas amostras, elas foram saturadas em bandejas, mantendo-se uma lâmina de água acima de dois terços da altura dos anéis. Essas amostras foram submetidas ao potencial mátrico $(\Psi)$ de -1, -6 e -8 kPa em uma mesa de tensão (Romano et al., 2002). Em seguida, as amostras foram secas em estufa a $\pm 105^{\circ} \mathrm{C}$ por $24 \mathrm{~h}$. A densidade do solo foi determinada conforme Grossman \& Reinsch (2002).

O indicador capacidade de armazenamento de água do solo foi calculado mediante as relações entre o conteúdo de água do solo retido no potencial equivalente à capacidade de campo ou $\Psi=-8 \mathrm{kPa}$ e a porosidade total do solo; já o indicador capacidade de aeração total do solo foi calculado mediante as relações entre a porosidade drenada entre a saturação e o $\Psi=-8 \mathrm{kPa}$ com a porosidade total do solo (Reynolds et al., 2002). A porosidade total do solo foi obtida como [1-(densidade do solo/densidade de partículas do solo)], tendo sido considerado o valor médio de $2,62 \mathrm{Mg} \mathrm{m}^{-3}$, da densidade de partículas do solo, determinado nas 216 amostras, conforme Embrapa (1997). Também foram realizadas as determinações propostas por Reynolds et al. (2002): porosidade no domínio dos macroporos, definida como o volume de poros drenados entre a saturação e o $\Psi=-1 \mathrm{kPa}$, equivalente aos poros com diâmetro $\geq 300 \mu \mathrm{m}$; porosidade no domínio da matriz do solo, definida pelo volume de poros com água no $\Psi=-8 \mathrm{kPa}$, equivalente aos poros com diâmetro $\leq 300 \mu \mathrm{m}$; e capacidade de aeração da matriz do solo, definida como o volume de poros drenados entre $\Psi=-1$ e $-8 \mathrm{kPa}$. Os valores de macroporosidade e microporosidade foram definidos pela drenagem e retenção de água no $\Psi=-6 \mathrm{kPa}$.

A amostragem de solo para a taxa de estratificação do C orgânico do solo foi realizada nas entrelinhas do pomar, sob o rodado e entrerrodado, 3,5 e 4,2 m à esquerda do tronco das laranjeiras (Figura 1), locais em que não haviam sido coletadas amostras de solo, desde a implantação dos tratamentos em 1993. As amostras de solo, compostas de três amostras simples, foram coletadas com cilindros de 10 e $8 \mathrm{~cm}$ de diâmetro (Fidalski \& Tormena, 2005), nas camadas de 0-5 cm e $10-15 \mathrm{~cm}$ de profundidade, respectivamente. A determinação dos teores de C orgânico do solo foi feita pelo método Walkley \& Black (Embrapa, 1997). A taxa de estratificação do $\mathrm{C}$ orgânico do solo foi calculada pelo quociente dos teores de $\mathrm{C}$ orgânico do solo da camada de 0-5 e 10-15 cm de profundidade, conforme Franzluebbers et al. (2002) e Mrabet (2002).

Os dados originais das variáveis das amostras de solo, por vegetação ou posição de amostragem, foram submetidos às análises de variâncias, por meio do modelo matemático de blocos ao acaso (Banzatto \& Kronka, 1989), e a testes de comparação de médias Tukey a $5 \%$. As análises estatísticas foram realizadas com o programa estatístico SAS Institute (2001). 


\section{RESULTADOS E DISCUSSÃO}

O tráfego de máquinas e equipamentos agrícolas resultou em maior densidade do solo sob o rodado, com maior compactação sendo observada no tratamento vegetação espontânea, em comparação ao tratamento gramínea (Quadro 1). A menor compactação nesses solos com essa gramínea também foi verificada em solo similar por Marun (1996). Esses resultados comprovam os efeitos deletérios à ação do tráfego de máquinas e equipamentos agrícolas verificados em pomares de macieira (Goh et al., 2001; Oliveira \& Merwin, 2001) e confirmados em pomar de laranjeira (Lima et al., 2004; Fidalski et al., 2007). A maior densidade do solo predispõe as raízes a estresse provocado pelo aumento da resistência do solo à penetração, atestado neste solo por Fidalski (2004), que constatou maiores valores de resistência à penetração do solo, em ordem crescente das vegetações: gramínea, leguminosa e espontânea.

Os sistemas de manejo das vegetações e posições de amostragem do solo estabeleceram alterações na porosidade, expressa pela macroporosidade, porosidade no domínio dos macroporos, porosidade no domínio da matriz e porosidade total do solo (Quadros 2 e 3). Contudo, a porosidade total do solo foi a variável que melhor distinguiu a condição física do solo das vegetações estudadas sob o rodado. Esses resultados diferem daqueles do estudo de Reynolds et al. (2002), por não terem verificado o efeito dos sistemas de manejo para esses indicadores em solo de textura arenosa. Atribui-se essa resposta diferenciada ao maior conteúdo de areia fina (Quadro 1), além da ausência de revolvimento do solo desde a implantação deste experimento, há 10 anos. Independentemente das alterações dos macroporos, observam-se, estatisticamente, menores valores da capacidade de aeração do solo da matriz do solo e a capacidade de aeração total sob o rodado das vegetações leguminosa e espontânea (Quadros 2 e 3), as quais atenderam ao limite mínimo de $0,10 \mathrm{~m}^{3} \mathrm{~m}^{-3}$, necessário para a difusão de gases e manutenção das atividades fisiológicas das raízes das plantas (Grable \& Siemer, 1968).

A avaliação dos indicadores de qualidade do solo proposta por Reynolds et al. (2002) evidenciou a importância na descrição da qualidade do solo por sistemas de manejo da vegetação e posição de amostragem de solo (Quadros 2 e 3 ). A porosidade de aeração da matriz do solo e aeração total do solo permitiu atender ao volume mínimo de poros para as funções de aeração das raízes das plantas sob o rodado e entrerrodado, subestimada se fosse utilizada a macroporosidade do solo sob o rodado (Quadro 2). A confirmação de que os indicadores de porosidade do solo propostos por Reynolds et al. (2002) atenderiam ao valor mínimo de $0,10 \mathrm{~m}^{3} \mathrm{~m}^{-3}$ e às funções fisiológicas das raízes das plantas foi feita neste experimento por meio do Intervalo Hídrico Ótimo (Fidalski, 2004), que, de acordo com Bengough et al. (2006), indica os riscos de estresses físicos durante o período de desenvolvimento das raízes das plantas.

Os indicadores capacidade de aeração do solo e capacidade de armazenamento de água do solo não se diferenciaram entre as vegetações, apenas entre as posições de amostragem de solo para as vegetações

Quadro 2. Indicadores de qualidade física do solo por vegetação e posição de amostragem rodado e entrerrodado

\begin{tabular}{cccccc}
\hline $\begin{array}{c}\text { Vegetação ou } \\
\text { tratamento }\end{array}$ & Densidade $\begin{array}{c}\text { Macro- } \\
\text { porosidade }\end{array}$ & $\begin{array}{c}\text { Micro- } \\
\text { porosidade }\end{array}$ & $\begin{array}{c}\text { Porosidade no } \\
\text { domínio dos } \\
\text { macroporos } \\
(\Phi \geq 300 \mu \mathrm{m})\end{array}$ & $\begin{array}{c}\text { Porosidade no } \\
\text { domínio da } \\
\text { matriz } \\
(\Phi \leq 300 \mu \mathrm{m})\end{array}$ & $\begin{array}{c}\text { Capacidade } \\
\text { de aeração } \\
\text { da matriz }\end{array}$ \\
\hline
\end{tabular}

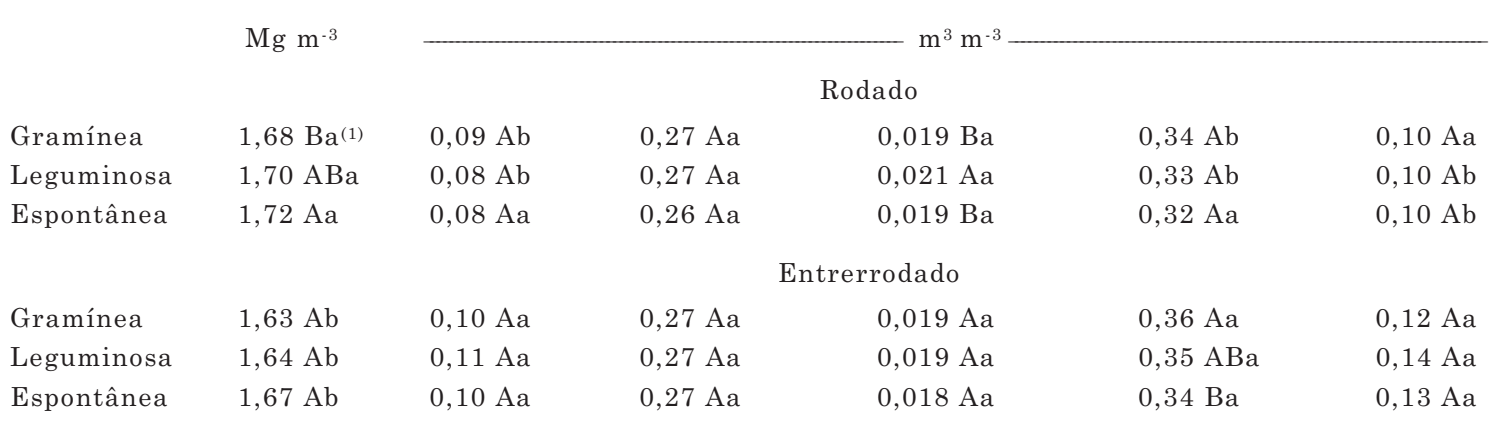

\footnotetext{
${ }^{(1)}$ Médias seguidas pela mesma letra maiúscula, na coluna, não diferem os tratamentos dentro da mesma posição de amostragem e médias seguidas pela mesma letra minúscula, na coluna, não diferem os tratamentos entre as posições de amostragem, pelo teste de Tukey a $5 \%$.
} 
Quadro 3. Indicadores de qualidade física do solo propostos por Reynolds et al. (2002), por vegetação e posição de amostragem rodado e entrerrodado

\begin{tabular}{|c|c|c|c|c|c|}
\hline $\begin{array}{c}\text { Vegetação ou } \\
\text { tratamento }\end{array}$ & $\begin{array}{c}\text { Capacidade de } \\
\text { aeração } \\
\text { total(A) }\end{array}$ & $\begin{array}{l}\text { Conteúdo de } \\
\text { água retido } \\
\psi=-8 \mathrm{kPa}(\mathrm{B})\end{array}$ & $\begin{array}{l}\text { Porosidade do } \\
\text { solo (C) }\end{array}$ & $\begin{array}{c}\text { Indicador da } \\
\text { capacidade de } \\
\text { aeração(A)/(C) }\end{array}$ & $\begin{array}{c}\text { Indicador da } \\
\text { capacidade de } \\
\text { armazenamento de } \\
\text { água(B)/(C) }\end{array}$ \\
\hline & & & Rodado & & \\
\hline Gramínea & $0,12 \mathrm{Aa}^{(1)}$ & $0,24 \mathrm{Aa}$ & $0,36 \mathrm{Ab}$ & $0,33 \mathrm{Aa}$ & $0,67 \mathrm{Aa}$ \\
\hline Leguminosa & $0,13 \mathrm{Ab}$ & $0,23 \mathrm{Aa}$ & $0,35 \mathrm{ABb}$ & $0,36 \mathrm{Ab}$ & $0,64 \mathrm{Aa}$ \\
\hline \multirow[t]{2}{*}{ Espontânea } & $0,12 \mathrm{Ab}$ & $0,23 \mathrm{Aa}$ & $0,34 \mathrm{Ba}$ & $0,34 \mathrm{Ab}$ & $0,66 \mathrm{Aa}$ \\
\hline & \multicolumn{5}{|c|}{ Entrerrodado } \\
\hline Gramínea & $0,14 \mathrm{Aa}$ & $0,23 \mathrm{Aa}$ & $0,38 \mathrm{Aa}$ & $0,37 \mathrm{Aa}$ & $0,63 \mathrm{Aa}$ \\
\hline Leguminosa & $0,16 \mathrm{Aa}$ & $0,22 \mathrm{Ab}$ & $0,37 \mathrm{Aa}$ & $0,42 \mathrm{Aa}$ & $0,58 \mathrm{Ab}$ \\
\hline Espontânea & $0,15 \mathrm{Aa}$ & $0,22 \mathrm{Ab}$ & $0,36 \mathrm{Aa}$ & $0,40 \mathrm{Aa}$ & $0,60 \mathrm{Ab}$ \\
\hline
\end{tabular}

(1) Médias seguidas pela mesma letra maiúscula, na coluna, não diferem os tratamentos dentro da mesma posição de amostragem e médias seguidas pela mesma letra minúscula, na coluna, não diferem os tratamentos entre as posições de amostragem, pelo teste de Tukey a $5 \%$.

leguminosa e espontânea sob o rodado (Quadro 3), e corresponderam aos valores indicados para uma boa qualidade do solo (Reynolds et al., 2002). No presente estudo, a utilização da gramínea como cobertura permanente conferiu igualdade desses dois indicadores entre o rodado e entrerrodado, ao passo que, com a leguminosa e a vegetação espontânea, verificou-se a heterogeneidade da capacidade de armazenamento de água do solo do rodado em direção ao entrerrodado, não diagnosticada pelas variáveis convencionalmente utilizadas, como densidade, macroporosidade e porosidade total do solo. A melhor homogeneidade da capacidade de armazenamento de água do solo entre o rodado e o entrerrodado sob gramínea é atribuída à maior produção de matéria seca de raízes sob a gramínea, comparada à leguminosa ou à vegetação espontânea (Doss et al., 1960; Espindola et al., 1998; Perin et al., 2002), que conferem maior resistência do solo à compactação.

A consolidação dos sistemas de manejo de solo proporcionada pela manutenção da cobertura do solo com a gramínea e leguminosa durante os últimos 10 anos indicou que as propriedades físicas da camada de $0-15 \mathrm{~cm}$ de profundidade não foram afetadas pelos teores de C orgânico do solo (Quadro 4), contrariando as afirmações de inúmeros autores (Hollis et al., 1977; Cintra et al., 1983; Kay \& VandenBygaart, 2002; Emerson \& McGarry, 2003; Rawls et al., 2003). Ressalta-se que o maior teor de $\mathrm{C}$ orgânico do solo na camada superficial de $0-5 \mathrm{~cm}$ de profundidade explicou a melhor qualidade física do solo sob a gramínea, comparada à vegetação espontânea (Quadros 2 e 4). $\mathrm{O}$ solo sob o sistema de manejo com vegetação leguminosa apresentou teores de C orgânico intermediários aos da vegetação gramínea e espontânea, atribuída à senescência da parte área dessa leguminosa durante o inverno, constituindo-se em uma resposta fisiológica ao estresse hídrico (Fischer \& Cruz, 1994).

Alternativamente, o indicador taxa de estratificação do $\mathrm{C}$ orgânico do solo, obtida das amostras de solo superiores e inferiores à camada intermediária de 0-15 cm (0-5 e 10-15 cm de profundidade), permitiram diferenciar estatisticamente os tratamentos com as vegetações gramínea e leguminosa do tratamento de manejo da vegetação espontânea, no rodado e entrerrodado (Quadro 4), respectivamente, em concordância com Mrabet (2002). Considerando a taxa de estratificação de C orgânico igual ou superior a duas unidades, sugeridas por Franzluebbers (2002), e por não ser comum encontrar solos degradados com valores superiores a estes, verifica-se que o manejo da vegetação espontânea com herbicida estaria comprometendo a qualidade física do solo. Por sua vez, o manejo das vegetações gramínea e leguminosa, ao apresentar taxa de estratificação do C orgânico do solo com valores superiores a duas unidades, confere melhor qualidade do solo sob rodado e entrerrodado (Quadros 2 e 3) e maior resistência à deformação e à compactação do solo (Soane, 1990).

A manutenção da vegetação leguminosa apresenta os maiores riscos de deficiência hídrica às plantas do pomar (Johns, 1994), indicada pelo desequilíbrio dos indicadores capacidade de aeração total do solo e capacidade de armazenamento de água do solo, o que é confirmado pelas determinações fisiológicas das laranjeiras (taxa de fotossíntese, condutância estomática e potencial da água das folhas de laranjeiras), hídricas (teor de água no solo) e mecânicas 
Quadro 4. Teores de carbono orgânico por camadas de solo e o indicador de qualidade física do solo taxa de estratificação de carbono orgânico do solo proposto por Franzluebbers (2002), por vegetação e posição de amostragem rodado e entrerrodado

Vegetação ou tratamento

\begin{tabular}{lrr} 
& & Carbono orgânico \\
\hline $0-15 \mathrm{~cm}$ & $0-5 \mathrm{~cm}$ & $10-15 \mathrm{~cm}$
\end{tabular}

(A)
(B)
Taxa de estratificação

(A)/(B)

\begin{tabular}{|c|c|c|c|c|}
\hline \multirow[b]{2}{*}{ Gramínea } & \multicolumn{4}{|c|}{ Rodado } \\
\hline & $5,37 \mathrm{Aa}$ & $10,15 \mathrm{Aa}$ & $4,27 \mathrm{Aa}$ & $2,39 \mathrm{Aa}$ \\
\hline Leguminosa & $5,02 \mathrm{Ab}$ & $8,09 \mathrm{ABa}$ & $3,54 \mathrm{Aa}$ & $2,30 \mathrm{Aa}$ \\
\hline \multirow[t]{2}{*}{ Espontânea } & $4,63 \mathrm{Aa}$ & $6,52 \mathrm{Ba}$ & $4,09 \mathrm{Aa}$ & $1,59 \mathrm{Ba}$ \\
\hline & \multicolumn{4}{|c|}{ Entrerrodado } \\
\hline Gramínea & $5,19 \mathrm{Aa}$ & $9,46 \mathrm{Aa}$ & 4,39 $\mathrm{Aa}$ & $2,17 \mathrm{ABa}$ \\
\hline Leguminosa & $5,35 \mathrm{Aa}$ & $8,54 \mathrm{ABa}$ & $3,75 \mathrm{Aa}$ & $2,31 \mathrm{Aa}$ \\
\hline Espontânea & $4,76 \mathrm{Aa}$ & $6,22 \mathrm{Ba}$ & $3,83 \mathrm{Aa}$ & $1,64 \mathrm{Ba}$ \\
\hline
\end{tabular}

\footnotetext{
(1) Médias seguidas pela mesma letra maiúscula, na coluna, não diferem os tratamentos dentro da mesma posição de amostragem e médias seguidas pela mesma letra minúscula, na coluna, não diferem os tratamentos entre as posições de amostragem, pelo teste de Tukey a $5 \%$.
}

(resistência do solo à penetração), monitoradas neste experimento por Fidalski (2004) e Fidalski et al. (2006). Em consonância com a tendência do manejo de pomares de frutas (Haynes, 1980; Butler, 1986; Hogue \& Neilsen, 1987; Lipecki \& Berbeć, 1997), os resultados indicam que o manejo da vegetação espontânea com herbicida resulta em maior risco à degradação da qualidade física do solo, os quais reiteram as recomendações do manejo nas entrelinhas dos pomares vegetados com gramínea, de acordo com Haynes (1980), Hogue \& Neilsen (1987) e Lipecki \& Berbeć (1997). Butler (1986) sugeriu a gramínea Paspalum notatum para pomares de plantas decíduas em solos de clima temperado, sendo observada em citros por Morgan et al. (2006). Em clima tropical, esta gramínea também é usada em pomares de laranjeiras (Auler et al., 2004; Fidalski \& Stenzel, 2006).

As plantas de cobertura Paspalum notatum e Arachis pintoi são duas espécies estoloníferas que asseguram maior taxa de cobertura ao solo e maior aporte de $\mathrm{C}$ orgânico do solo na camada de $0-5 \mathrm{~cm}$ de profundidade (Quadro 4), também verificado nesses solos por Fidalski \& Stenzel (2006). A interpretação da qualidade física deste solo pelo seu teor de C orgânico e pela taxa de estratificação do C orgânico do solo sugere que estes dois sistemas de manejo de solo são os mais apropriados para a cultura da laranjeira, comparados ao manejo tradicional da vegetação espontânea com herbicida, considerando-se o critério decisório de mais de duas unidades, conforme Franzluebbers (2002), o que é confirmado pela melhor qualidade física do solo (Quadros 2 e 3). Por sua vez, o indicador armazenamento de água do solo permite diferenciar a superioridade da vegetação gramínea em relação à leguminosa (Quadro 3), diante da melhor homogeneidade hídrica entre o rodado e o entrerrodado na entrelinha do pomar. A constatação da melhor qualidade física do solo proporcionada com a manutenção de gramíneas nas entrelinhas foi confirmada pelas melhores relações hídricas e metabólicas observadas nas laranjeiras do que na vegetação leguminosa e espontânea, sem comprometimento da produção de frutos das laranjeiras por qualquer uma das vegetações (Fidalski et al., 2006).

Com os recentes avanços metodológicos dos indicadores de qualidade física do solo proporcionados por Franzluebbers (2002) e Reynolds et al. (2002), associados às avaliações das determinações fisiológicas realizadas neste experimento por Fidalski et al. (2006) e à melhor qualidade física do solo sob rodado e entrerrodado (Quadros 2, 3 e 4), contestam-se os estudos de sistemas de manejo de citros que afirmaram o comprometimento da produção de frutos de laranjeiras quando manejadas com gramínea (Rodriguez et al., 1964; Dornelles, 1971; Pacheco et al., 1975; Wright et al., 2003). Outro aspecto relevante do sistema de manejo da cobertura do solo com gramínea nas entrelinhas do pomar, com a manutenção do solo sem revolvimento, é a redução das perdas de solo e de água nesses solos (Iapar, 1982; Fidalski, 1997b), que foram observadas na fase inicial da implantação dos pomares de laranjeira na região noroeste do Paraná, resultando na proposta de manutenção da cobertura permanente nas entrelinhas por Rufino et al. (1992) e na implantação do presente estudo; tampouco haveria a necessidade do revolvimento desses solos para incorporação do 
calcário, diante da eficiência da calagem superficial nas entrelinhas com gramínea, atestada por Fidalski \& Tormena (2005). Ao mesmo tempo, é descartado o revolvimento desses solos para reduzir a compactação sob o rodado, diante da constatação da melhoria da qualidade física do solo sob rodado com gramínea, que assegura menor densidade do solo e estabelece melhores funções do solo, expressas pela capacidade de aeração do solo e capacidade de armazenamento de água do solo (Quadros 2 e 3).

A comprovação de que a qualidade física do solo sob a vegetação da gramínea assegurou as funções de armazenamento de água do solo e, por sua vez, manteve maior atividade fisiológica das laranjeiras no período de maior deficiência hídrica é atribuída ao melhor aproveitamento da água armazenada na subsuperfície nos horizontes com textura média (Bt e $\mathrm{Bw})$, abaixo dos horizontes superficiais arenosos a $25 \mathrm{~cm}$ de profundidade (Quadro 1) (Fidalski et al., 2006), consistindo em uma das estratégias para contornar os períodos de estresse hídrico do solo, em oposição à proposta de irrigação nesse agroecossistema citrícola sugerida por Calheiros et al. (1992).

\section{CONCLUSÕES}

1. Os indicadores de qualidade do solo capacidade de armazenamento de água do solo, capacidade de aeração do solo e taxa de estratificação de C orgânico do solo foram eficientes na avaliação de sistemas de manejo de solo em citros.

2. A manutenção da vegetação nas entrelinhas vegetadas com a gramínea mato-grosso ou batatais (Paspalum notatum) melhora a qualidade física do solo, independentemente das posições rodado e entrerrodado.

3. A qualidade física do solo é afetada negativamente na posição rodado sob manejo com amendoim forrageiro (Arachis pintoi) e nas posições rodado e entrerodado no manejo tradicional da vegetação espontânea com herbicida pós-emergente.

\section{AGRADECIMENTO}

Ao citricultor e Engenheiro Agrônomo Osmar Inácio Ferrari e família, pela cessão e manuteção da área experimental.

\section{LITERATURA CITADA}

AULER, P.A.M.; FIDALSKI J.; PAVAN, M.A.; GOMES, J.C. \& JACOMINO, A.P. Sistema de preparo do solo, calagem e porta-enxertos para a produção de laranja Valência na região noroeste do Paraná. In: CONGRESSO BRASILEIRO DE FRUTICULTURA., 18., Florianópolis, 2004. Anais. Florianópolis, Sociedade Brasileira de Fruticultura, 2004. CD-ROM
BANZATTO, D.A. \& KRONKA, S.N. Experimentação agrícola. Jaboticabal, Funep, 1989. 247p.

BENGOUGH, A.G.; BRANSBY, M.F.; HANS, J.; McKENNA, S.J.; ROBERTS, T.J. \& VALENTINE, T.A. Root responses to soil physical conditions; growth dynamics from field to cell. J. Exp. Bot., 57:437-447, 2006.

BUTLER, J.D. Grass interplanting in horticulture cropping systems. HortScience, 21:394-397, 1986.

CALHEIROS, R.O.; OLIVEIRA, D.; CARAMORI, P.H. \& GROSSI, M.E.D. Viabilidade técnica da irrigação em citros no norte e noroeste do Paraná. Pesq. Agropec. Bras., 27:963-973, 1992

CHRISTENSEN B.T. \& JOHNSTON A.E. Soil organic matter and soil quality: Lessons learned from long-term experiments at Askov and Rothamsted. In: GREGORICH, E.G. \& CARTER, M.R., eds. Soil quality for crop production and ecosystem health. Amsterdam, Elsevier, 1997. p.399430.

CINTRA, F.L.D.; COELHO, Y.S.; CUNHA SOBRINHO, A.P. \& PASSOS, O.S. Caracterização física do solo submetido a práticas de manejo em pomar de laranja 'Baianinha'. Pesq. Agropec. Bras., 18:173-179, 1983.

DORNELLES, C.M.M. Manejo de solos em pomares de laranjeiras no Rio Grande do Sul. Sulriograndense, 7:9198, 1971.

DOSS, B.D.; ASHLEY, D.A. \& BENNETT, O.L. Effect of soil moisture regime on root distribution of warm season forage species. Agron. J., 52:569-572, 1960.

EMERSON, W.W. \& McGARRY, D. Organic carbon and soil porosity. Aust. J. Soil Res., 41:107-118, 2003.

EMPRESA BRASILEIRA DE PESQUISA AGROPECUÁRIA EMBRAPA. Manual de métodos de análises de solo. 2.ed. Rio de Janeiro, Centro Nacional de Pesquisa de Solos, 1997. 212p.

EMPRESA BRASILEIRA DE PESQUISA AGROPECUÁRIA EMBRAPA. Serviço Nacional de Levantamento e Conservação de Solos. Levantamento de reconhecimento dos solos do Estado do Paraná. Londrina, 1984. v.1/2. 791p. (Embrapa-SNLCS. Boletim de Pesquisa, 27; IAPAR. Boletim Técnico, 16)

EMPRESA BRASILEIRA DE PESQUISA AGROPECUÁRIA EMBRAPA. Sistema Brasileiro de Classificação de Solos. 2.ed. Rio de Janeiro, Embrapa Solos, 2006. 306p.

ESPINDOLA, J.A.A.; ALMEIDA, D.L.; GUERRA, J.G.M.; SILVA, E.M.R. \& SOUZA, F.A. Influência da adubação verde na colonização micorrízica e na produção da batatadoce. Pesq. Agropec. Bras., 33:339-347, 1998.

FIDALSKI, J. Diagnóstico de manejo e conservação do solo e da água na região noroeste do Paraná. R. Unimar, 19:845$851,1997 \mathrm{~b}$.

FIDALSKI, J. Fertilidade do solo sob pastagens, lavouras anuais e permanentes na região noroeste do Paraná. R. Unimar, 19:853-861, 1997a.

FIDALSKI, J. Propriedades físico-hídricas de um Argissolo Vermelho distrófico latossólico em diferentes sistemas de manejo das entrelinhas de citros. Maringá, Universidade Estadual de Maringá, 2004. 62p. (Tese de Mestrado) 
FIDALSKI, J.; TORMENA, C.A. \& SACAPIM, C.A Espacialização vertical e horizontal dos indicadores de qualidade para um Latossolo Vermelho cultivado com citros. R. Bras. Ci. Solo, 31:9-19, 2007.

FIDALSKI, J. \& STENZEL, N.M.C. Nutrição e produção da laranjeira "Folha Murcha" em porta-enxertos e plantas de cobertura permanente na entrelinha. Ci. Rural, 36:807813, 2006.

FIDALSKI, J. \& TORMENA, C.A. Dinâmica da calagem superficial em um Latossolo Vermelho distrófico. R. Bras. Ci. Solo, 29:235-247, 2005.

FIDALSKI, J.; MARUR, C.J.; AULER, P.A.M. \& TORMENA, C.A. Produção de laranja com plantas de cobertura permanente na entrelinha. Pesq. Agropec. Bras., 41:927. 935, 2006.

FIDALSKI, J.; PAVAN, M.A.; AULER, P.A.M. \& JACOMINO, A.P. Produção de frutos de laranjeira Pêra e teores de nutrientes nas folhas e no solo, em Latossolo VermelhoEscuro do noroeste do Paraná. R. Bras. Ci. Solo, 23:273279, 1999.

FISCHER, M.J. \& CRUZ, P. Some ecophysiological aspects of Arachis pintoi. In.: KERRIDGE, P.C. \& HARDY, B., eds. Biology and agronomy of forage Arachis. Cali, Centro Internacional de Agricultura Tropical, 1994. p.53-70. (CIAT. Publication, 20)

FRANZLUEBBERS, A.J. Soil organic matter stratification ratio as an indicador of soil quality. Soil Till. Res., 66:95106, 2002.

GOH, K.M.; PEARSON, D.R. \& DALY, M.J. Effects of apple orchard production systems on some important soil physical, chemical and biological quality parameters. Biol. Agric. Hortic., 18:269-292, 2001.

GRABLE, A.R. \& SIEMER, E.G. Effects of bulk density, aggregate size, and soil water suction on oxygen diffusion, redox potentials and elongation of corn roots. Soil Sci. Soc. Am. J., 32:180-186, 1968.

GROSSMAN, R.B. \& REINSCH, T.G. Bulk density and linear extensibility. In: DANE, J.H. \& TOPP, C., eds. Methods of soil analysis: Physical methods. Madison, Soil Science Society of America, 2002. v.4. p.201-228.

GRUPO PAULISTA DE ADUBAÇÃO E CALAGEM PARA CITROS. Recomendações de adubação e calagem para citros no Estado de São Paulo. 3.ed. Laranja, 1994. 27 p. (Edição Especial)

HAYNES, R.J. Influence of soil management practice on the orchard agro-ecosystem. Agro-Ecosyst., 6:3-32, 1980.

HOGUE, E.J. \& NEILSEN, G.H. Orchard floor vegetation management. Hortic. Rev., 9:377-430, 1987.

HOLLIS, J.M.; JONES, R.J.A. \& PALMER, R.C. The effects of organic matter and particle size on the water-retention properties of some soils in the West Midlands of England. Geoderma, 17:225-238, 1977.

INSTITUTO AGRONÔMICO DO PARANÁ - IAPAR. A citricultura no Paraná. Londrina, 1992. 288p. (IAPAR. Circular, 72)
INSTITUTO AGRONÔMICO DO PARANÁ - IAPAR. Cartas climáticas do Paraná: Edição ano 2000, versão 1.0. Londrina, 2000. CD-ROM

INSTITUTO AGRONÔMICO DO PARANÁ - IAPAR. Relatório técnico anual 1981. Londrina, 1982. 270p.

JOHNS, G.G. Effects of Arachis pintoi groundcover on performance of bananas in northern New South Wales. Aust. J. Exp. Agric., 34:1197-1204, 1994.

KARLEN, D.L.; ANDREWS, S.S. \& DORAN, J.W. Soil quality: Current concepts and applications. Adv. Agron., 74:1-40, 2001.

KARLEN, D.L.; MAUSBACH, M.J.; DORAN, J.W.; CLINE, R.G.; HARRIS, R.F. \& SCHUMAN, G.E. Soil quality: A concept, definition, and framework for evaluation. Soil Sci. Soc. Am. J., 61:4-10, 1997.

KAY, B.D. \& VANDENBYGAART, A.J. Conservation tillage and depth stratification of porosity and soil organic matter. Soil Till. Res., 66:107-118, 2002.

KOLLER, O.C.; BARRADAS, C.I.N. \& PEREIRA, A. Efeito de dois sistemas de manejo do solo sobre a produção de duas variedades de laranjeira doce Citrus sinensis, Osb. In: CONGRESSO BRASILEIRO DE FRUTICULTURA, 4., Salvador, 1977. Anais. Cruz das Almas, Sociedade Brasileira de Fruticultura, 1978. p.183-190.

LETEY, J. Relationship between soil physical properties and crop production. Adv. Soil Sci., 1:277-294, 1985.

LIMA, C.L.R.; SILVA, A.P.; IMHOFF. S.; LIMA, H.V. \& LEÃO, T.P. Heterogeneidade da compactação de um Latossolo Vermelho-Amarelo sob pomar de laranja. R. Bras. Ci. Solo, 28:409-414, 2004.

LIPECKI, J. \& BERBEĆ, S. Soil management in perennial crops: Orchards and hop gardens. Soil Till. Res., 43:169184, 1997.

MARUN, F. Propriedades físicas e biológicas de um Latossolo Vermelho-Escuro do arenito Caiuá sob pastagem e culturas anuais. Pesq. Agropec. Bras., 31:593-597, 1996.

MORGAN, K.T.; OBREZA, T.A.; SCHOLBERG, J.M.S.; PARSONS, L.R. \& WHCATON, T.A. Citrus water uptake dynamics on a sandy Florida Entisol. Soil Sci. Soc. Am. J., 70:90-97, 2006.

MRABET, R. Stratification of soil aggregation and organic matter under conservation tillage systems in Africa. Soil Till. Res., 66:119-128, 2002.

OLIVEIRA, M.T. \& MERWIN, I.A. Soil physical conditions in a New York orchard after eight years under different groundcover management systems. Plant Soil, 234:233237, 2001.

PACHECO, E.B.; SILVA, T.C.A.; SANTOS, H.L.; FELDMANN, R.O. \& TEIXEIRA, S.L. Efeito do manejo de um Latossolo Vermelho Amarelo, fase cerrado, sobre o crescimento e produção da laranjeira (Citrus sinensis Osbeck cv. 'Baianinha'). Experimentiae, 19:211-238, 1975. 
PERIN, A.; GUERRA, J.G.M.; TEIXEIRA, M.G.; PEREIRA, M.G. \& FONTANA, A. Efeito da cobertura viva com leguminosas herbáceas perenes na agregação de um Argissolo. R. Bras. Ci. Solo, 26:713-720, 2002.

RAWLS, W.J.; PACHEPSKY, Y.A.; RITCHIE, J.C.; SOBECKI, T.M. \& BLOODWORTH, H. Effect of soil organic carbon on soil water retention. Geoderma, 116:61-76, 2003.

REYNOLDS, W.D.; BOWMAN, B.T.; DRURY, C.F.; TAN, C.S \& LU, X. Indicators of good soil physical quality: density and storage parameters. Geoderma, 110:131-146, 2002.

RODRIGUEZ, O.; MOREIRA, S. \& ROESSING, C. Estudo de nove práticas de cultivo do solo em pomar cítrico no planalto Paulista. Cruz das Almas, IPEAS, 1964. p.257. 258 (Boletim Técnico, 2)

ROMANO, N.; HOPMANS, J.W. \& DANE, J.H. Suction table. In: DANE, J.H. \& TOPP, C., eds. Methods of soil analysis: Physical methods. Madison, Soil Science Society of America, 2002. v.4. p.692-698.

RUFINO, R.L.; MUZILLI, O. \& PAVAN, M.A. Manejo do solo. In: INSTITUTO AGRONÔMICO DO PARANÁ. A citricultura no Paraná. Londrina, 1992. p.53-90. (IAPAR. Circular, 72)
SANCHES, A.C.; SILVA, A.P.; TORMENA, C.A. \& RIGOLIN, A.T. Impacto do cultivo de citros em propriedades químicas, densidade do solo e atividade microbiana de um Podzólico Vermelho-Amarelo. R. Bras. Ci. Solo, 23:91-99, 1999.

SAS INSTITUTE. SAS/STAT User's guide. Version 8.2. Cary, 2001. 943p.

SKOPP, J.; JAWSON, M.D. \& DORAN, J.W. Stead-state aerobic microbial activity as a function of soil water content. Soil Sci. Soc. Am. J., 54:1619-1625, 1990.

SOANE, B.D. The role of organic matter in soil compactability: A review of some practical aspects. Soil Till. Res., 16:179201,1990

TOPP, G.C. \& ZEBCHUK, W. The determination of soil-water desorption curves for soil cores. Can. J. Soil Sci., 59:1926, 1979.

TORMENA, C.A.; FRIEDRICH, R.; PINTRO, J.C.; COSTA, A.C.S. \& FIDALSKI, J. Propriedades físicas e taxa de estratificação de C orgânico num Latossolo Vermelho após dez anos sob dois sistemas de manejo. R. Bras. Ci. Solo, 28:1023-1031, 2004.

WRIGHT, G.C.; McCLOSKEY, W.B \& TAYLOR, K.C. Managing orchard floor vegetation in flood-irrigated citrus groves. HortTechnology, 13:668-677, 2003. 